\title{
The use of phage FCL-2 as an alternative to chemotherapy against columnaris disease in aquaculture
}

\author{
Elina Laanto ${ }^{1 *}$, Jaana K. H. Bamford ${ }^{1}$, Janne J. Ravantti1,2 and Lotta-Riina Sundberg' ${ }^{1}$ \\ ${ }^{1}$ Centre of Excellence in Biological Interactions, Department of Biological and Environmental Science, University of Jyvaskyla, \\ Jyvaskyla, Finland, ${ }^{2}$ Department of Biosciences and Institute of Biotechnology, University of Helsinki, Helsinki, Finland
}

\section{OPEN ACCESS}

Edited by:

Hongyue Dang,

Xiamen University, China

Reviewed by: Roberto Bastías,

Pontifical Catholic University of Valparaíso, Chile Darren Lee Smith,

University of Northumbria at Newcastle, UK

*Correspondence:

Elina Laanto,

Centre of Excellence in Biological Interactions, Department of Biological and Environmental Science, University

of Jyvaskyla, P.O. Box 35,

Fl-40014 Jyvaskyla, Finland elina.laanto@jyu.fi

Specialty section: This article was submitted to Aquatic Microbiology, a section of the journal Frontiers in Microbiology

Received: 17 June 2015

Accepted: 28 July 2015

Published: 19 August 2015

Citation:

Laanto E, Bamford JKH, Ravantti J and Sundberg L-R (2015) The use

of phage FCL-2 as an alternative to chemotherapy against columnaris disease in aquaculture.

Front. Microbiol. 6:829. doi: 10.3389/fmicb.2015.00829
Flavobacterium columnare, the causative agent of columnaris disease in fish, causes millions of dollars of losses in the US channel catfish industry alone, not to mention aquaculture industry worldwide. Novel methods are needed for the control and treatment of bacterial diseases in aquaculture to replace traditionally used chemotherapies. A potential solution could be the use of phages, i.e., bacterial viruses, host-specific and self-enriching particles that can be can easily distributed via water flow. We examined the efficacy of phages to combat columnaris disease. A previously isolated phage, FCL-2, infecting F. columnare, was characterized by sequencing. The $47142 \mathrm{bp}$ genome of the phage had $\mathrm{G}+\mathrm{C}$ content of $30.2 \%$, and the closest similarities regarding the structural proteins were found in Cellulophaga phage phiSM. Under controlled experimental conditions, two host fish species, rainbow trout (Oncorhynchus mykiss) and zebrafish (Danio rerio), were used to study the success of phage therapy to prevent F. columnare infections. The survival of both fish species was significantly higher in the presence of the phage. Hundred percent of the zebrafish and $50 \%$ of the rainbow trout survived in the phage treatment (survival without phage 0 and $8.3 \%$, respectively). Most importantly, the rainbow trout population was rescued from infection by a single addition of the phage into the water in a flow-through fish tank system. Thus, F. columnare could be used as a model system to test the benefits and risks of phage therapy on a larger scale.

Keywords: aquaculture, disease, fish, Flavobacterium columnare, phage therapy

\section{Introduction}

In 2014, the WHO (2014) reported high rates of antimicrobial resistance in common diseasecausing bacteria in all regions of the world. Concerns of antibiotic resistance have also brought attention to the large amounts of antibiotics used in animal production, also in aquaculture (Buschmann et al., 2012; Hollis and Ahmed, 2013). Antibiotics used in aquaculture may dissolve from the fish feed to the surrounding water (Cabello et al., 2013), thus enabling the development of antibiotic resistance in environmental microbes (Buschmann et al., 2012; Di Cesare et al., 2013). Indeed, concentrations of typically used antimicrobials (e.g., tetracycline) in marine sediments can be higher than the minimal inhibitory concentrations for most bacteria (reviewed in Cabello et al., 2013). 
As aquaculture is the fastest growing industry for animal protein production in the world (Bostock et al., 2010), novel methods are needed for management of bacterial diseases. One option is phage therapy, which is already considered a feasible substitute for antibiotics in healthcare, livestock, and crop production (Smith and Huggins, 1983; Berchieri et al., 1991; Barrow et al., 1998; Nakai and Park, 2002; Jamalludeen et al., 2009; Santos et al., 2010; Abedon et al., 2011; Jones et al., 2012). Although the risk of development of phage resistance in the target bacteria needs to be considered, by e.g., using multiphage cocktails, phage therapy has great potential in the treatment of aquatic organisms. In contrast to antibiotics, phages are host-specific and self-enriching particles that can be can easily distributed via water flow within rearing units.

Columnaris disease (caused by Flavobacterium columnare, Bacteroidetes) is a significant problem in freshwater fish farming worldwide (Pulkkinen et al., 2010; Declercq et al., 2013). Currently, fish with columnaris disease are treated with antibiotics. Columnaris disease is a good candidate target for phage therapy since the disease is mainly external (on the fish gills, fins, and skin; Bernardet, 1997; Tripathi et al., 2005) and the bacteria transmit through water (Welker et al., 2005; Kunttu et al., 2009). The present study characterizes a phage, FCL-2 (Laanto et al., 2011), infecting F. columnare and examines how the phage treatment affects columnaris disease in rainbow trout (Oncorhynchus mykiss) and zebrafish (Danio rerio) under experimental conditions. We show that the phage can significantly alter the outcome of infection by F. columnare. In addition to proving its functionality in a specific system, this study highlights the use of $F$. columnare and its phage as a model for the implementation of phages as a treatment, namely phage therapy, in a real disease context in a real host. This system could also be used to estimate the possible (environmental) side effects of the method in practice, such as the effect of the presence of fish host and antibiotic treatments on evolution of phage resistance, or the effect of phage additions on natural bacterial community.

\section{Materials and Methods}

\section{Bacteria and Phage}

Flavobacterium columnare strain B185 and phage FCL-2 were both isolated from a fish farm rearing mainly salmonid fingerlings during a columnaris outbreak in 2008 (Laanto et al., 2011). Bacteria and phage were cultured in Shieh medium (Decostere et al., 1997), without tobramycin $\left(24^{\circ} \mathrm{C}, 110 \mathrm{rpm}\right)$ and stored in $10 \%$ glycerol and $10 \%$ fetal calf serum at $-80^{\circ} \mathrm{C}$. The optical density of B185 was measured at $570 \mathrm{~nm}$ to determine the colony forming units (CFU) per mL based on our unpublished analyses. For plaque assays the "double layer agar" -method (Adams, 1959) was used as follows: melted top agar $(0.7 \%)$ including $300 \mu \mathrm{L}$ of host bacterium and $100 \mu \mathrm{L}$ of phage dilution was poured on Shieh agar and grown for $48 \mathrm{~h}$ at room temperature. Phage stocks were prepared from Shieh agar plates with confluent lysis by adding $5 \mathrm{~mL}$ of Shieh-medium on top of a plate and incubated at $6^{\circ} \mathrm{C}$ for $6 \mathrm{~h}$. The lysate was collected, filtered, and stored at $+4^{\circ} \mathrm{C}$ and for longer periods at $-80^{\circ} \mathrm{C}$ with $10 \%$ glycerol. Phage morphology was studied previously (Laanto et al., 2011), but a higher quality transmission electron microscope was obtained for this study (Jeol JEM-1400 at $80 \mathrm{kV}$ ). For transmission electron microscopy (TEM) analysis, the phage was pelleted (Beckman coulter L-90K, 70 Ti-rotor, $25000 \times g, 2 \mathrm{~h},+4^{\circ} \mathrm{C}$ ) and washed twice with $0.1 \mathrm{M}$ ammonium acetate, pelleted as above and suspended in $0.02 \mathrm{M}$ potassium phosphate. The phage was spotted on a coppercoated grid for $2 \mathrm{~min}$ and excess suspension was dried with filter paper. Ten microliters of $1 \%$ phosphotungstate, at $\mathrm{pH} 6.5$, were applied on the grid for $1 \mathrm{~min}$ and the grid was dried with filter paper.

\section{Phage Adsorption and Stability}

The phage adsorption rate was measured in three replicates in $1 \mathrm{~mL}$ of Shieh medium with logarithmic phase B185 cells $\left(1.4 \times 10^{8} \mathrm{CFU}\right)$, with a doubling time of approximately $10 \mathrm{~h}$ at RT (Zhang et al., 2014). Phage $\left(2.2 \times 10^{4} \mathrm{PFU}\right.$, resulting to a MOI of $1.6 \times 10^{-4}$ ) was added to each tube and tubes were shaken and then left to stand at RT; the control contained only the medium without cells. The bacterium-phage mixture was pelleted after 1 , $5,10,20,40$, and $60 \mathrm{~min}$ by centrifugation $(15000 \times g)$ and the PFU mL $\mathrm{mL}^{-1}$ of the free phage particles in the supernatant at each time point was determined to calculate the corresponding number of adsorbed phage particles. The adsorption rate was determined as the exponential decrease of free phage particles during the time of incubation.

The phage ability to remain infective in different buffers was tested by diluting FCL-2 lysate (original $1.2 \times 10^{11} \mathrm{PFU} \mathrm{mL}^{-1}$ ) at a ratio of 1:100 in Shieh medium, into $20 \mathrm{mM}$ Tris- $\mathrm{HCl}$ ( $\mathrm{pH} 6.1,7.6$, and 8.1 ) and $20 \mathrm{mM}$ potassium phosphate $(\mathrm{pH}$ 6.0, 7.2, and 8.0). All dilutions were kept at $6^{\circ} \mathrm{C}$ (and one dilution in Shieh medium at room temperature) for 6 weeks and PFU $\mathrm{mL}^{-1}$ was determined after 1 and 6 weeks as described above.

\section{Phage Genome Sequencing}

The protocol developed by Santos (Santos, 1991), with slight modifications, was used to isolate phage DNA from the phage lysate. Briefly, phage particles were precipitated by adding $40 \mathrm{mM}$ $\mathrm{ZnCl}_{2}$ and incubating for $5 \mathrm{~min}$, followed by pelleting of the phage precipitate $(15000 \times \mathrm{g}, 5 \mathrm{~min})$. DNA was purified using a GeneJET ${ }^{\mathrm{TM}}$ Genomic DNA isolation kit column (Fermentas). The phage genome was sequenced in two platforms (Ion Torrent PGM with 100 bp kit and commercially with Roche 454 at LGC Genomics, Germany) and the data were combined because neither of the methods resulted in whole genome sequence. Initially, in-house Ion Torrent run was used for de novo assembly. Since the assembly did not yield a single contig, we decided to try to improve the assembly by using also commercial paired-end 454 sequencing. All analyses were done using GS De Novo Assembler version 2.9 (454 Life Sciences; Roche) which uses Overlap Layout Consensus (OLC) methodology. Open reading frames (ORFs) were predicted using Glimmer and GeneMarkS, and similar sequences were searched from databases using BLAST (Altschul et al., 1990) with Geneious version 7.1 (created by Biomatters Ltd). 
Fish Experiments with Zebrafish (Danio rerio) and Rainbow Trout (Oncorhynchus mykiss)

Fish experiments were conducted according to the Finnish Act on Use of Animals for Experimental Purposes, under permission EASVI-2010-05569/Ym-23 granted for L-RS by the National Animal Experiment Board at the Regional State Administrative Agency for Southern Finland. Unsexed, adult, disease-free zebrafish (D. rerio) were obtained from the core facilities and research services of Tampere (Tampere University, Finland). Prior to the experiments, the zebrafish were maintained in $250-\mathrm{L}$ aquaria containing aerated ground water at $25^{\circ} \mathrm{C}$. Rainbow trout (O. mykiss) fry with no previous contact with F. columnare were obtained from a fish farm in central Finland (approximate weight in the experiments $0.57 \mathrm{~g}$ ). Prior to the experiments, the rainbow trout were maintained in aerated ground water at $17^{\circ} \mathrm{C}$ in $250-\mathrm{L}$ flow-through aquaria. For the infection experiments, the water temperature of rainbow trout was gradually elevated to $24^{\circ} \mathrm{C}$ over 7 days. Two infection methods were used. Zebrafish were infected by applying $F$. columnare directly to the experimental aquaria, resulting in continuous infection. The bacterial levels used for infection were chosen based on our previous studies on rainbow trout (see, e.g., Kunttu et al., 2009) and on zebra fish (Laanto et al., 2012; Zhang et al., 2014). Rainbow trout populations were immersed in water containing the bacterium for $2 \mathrm{~h}$, after which fish were transferred to experimental aquaria. The fish were monitored in 2-hour intervals in the zebrafish experiment and in 12-hour intervals in the rainbow trout population experiment. Fish aquaria had running numbers and were mixed after addition of phage. Morbid fish that did not respond to stimuli were considered dead and removed from the experiment. In all experiments, fin cultivations on Shieh agar supplemented with tobramycin were taken from moribund fish to determine the presence/absence of $F$. columnare on the fish.

\section{Measuring the Effect of Phage Addition to a Flow-Through System with Rainbow Trout Population Infected with F. columnare}

For infection, the rainbow trout fry $(n=260)$ were divided into 13 groups of 20 fish, and placed in 3-L aquaria containing $2 \mathrm{~L}$ of ground water. Nine fish grpups were exposed to $3 \times 10^{6} \mathrm{CFU} \mathrm{mL} \mathrm{m}^{-1}$ of $F$. columnare (calculated from optical density at $570 \mathrm{~nm}$ based on the data from unpublished experiments) and four control groups to sterile Shieh medium for $2 \mathrm{~h}$ under aeration at $24.2^{\circ} \mathrm{C}$. After the challenge, fish populations were transferred to experimental aquaria containing $2 \mathrm{~L}$ of ground water with a constant inflow of fresh water $\left(\sim 0.6 \mathrm{~L} \mathrm{~min}{ }^{-1}\right.$, resulting in an approximately $3.3 \mathrm{~min}$ turnover time of the whole water body) and aeration, at a temperature ranging from 23.7 to $24.4^{\circ} \mathrm{C}$ during the experiment. The phage was added to experimental aquaria after fish transfer with phageto-bacterium ratios of 1:1 (three aquaria) and 10:1 (three aquaria) compared to infection dose, and the highest amount was added to two control aquaria with fish exposed to Shieh medium. During phage addition, the water flow was stopped for $60 \mathrm{~min}$ for all of the aquaria. Fish were monitored for 7 days in 12-hour intervals.
During the experiment, water samples were taken after 24 and $48 \mathrm{~h}$ from the start of the experiment to determine the number of $F$. columnare cells $\left(\mathrm{CFU} \mathrm{mL}^{-1}\right.$ ) and FCL-2 phages $\left(\mathrm{PFU} \mathrm{mL} \mathrm{m}^{-1}\right)$ in the water. Samples were taken from two aquaria from the following treatments: phage-to-bacterium ratios 1:1 and 10:1, phage control, and bacterial control. Water samples were diluted and plated on a Shieh agar plate supplemented with tobramycin (Decostere et al., 1997) and F. columnare colonies were counted after a 48-hour incubation at room temperature. PFU were determined from the same dilution series by culturing $300 \mu \mathrm{L}$ of host bacterium and phage sample dilutions in Shieh soft agar, as described above.

\section{Effect of Phage Addition in Experimental $\boldsymbol{F}$. columnare Infection of Individual Zebrafish}

Zebrafish $(n=60)$ were placed individually in $1-\mathrm{L}$ aquaria containing $500 \mathrm{~mL}$ of ground water $\left(24.4^{\circ} \mathrm{C}\right)$. Fish $(n=40)$ were infected in continuous exposure with $5 \times 10^{4} \mathrm{CFU} \mathrm{mL} \mathrm{mL}^{-1}$ of F. columnare. The phage was added to 20 of these aquaria directly after infection at a phage-to-bacteria cell ratio of $1: 1$. Phageto-bacteria ratio from $0,1: 1$ to $100: 1$ was tested in preliminary studies. There was no clear difference between ratios of 1:1 and $1: 100$, therefore the lowest ratio that had an effect to fish survival was chosen. Control fish received sterile Shieh medium $(n=10)$ and phage only $(n=10)$. The total volume addition to each aquarium was $500 \mu \mathrm{L}$.

\section{Statistical Analysis}

Fish survival in experimental infections was analyzed using IBMSPSS statistics 20 . The fish survival was analyzed with KaplanMeier survival analysis.

\section{Phage Genome Accession Number}

The nucleotide sequence of the FCL-2 phage genome has been deposited to GenBank (accession number KM873719).

\section{Results}

\section{Phage Characterization and Genome Analysis}

Phage FCL-2 has been previously determined as a member of Myoviridae (Laanto et al., 2011). TEM analysis revealed the diameter of the icosahedral capsid to be $55-60 \mathrm{~nm}$. The tail was approximately $85 \mathrm{~nm}$ long. A prominent neck was visible and tail fibers could be seen (Figure 1). Enrichment of the phage was done on plates because despite of optimization of culture conditions and parameters, the cells infected with phage have not lysed under liquid culture.

Sequence of the FCL-2 genome was obtained by combining Ion Torrent and 454 data. Using both data sets (total number of sequences: 34680; total number of bases: 6155764) we were able to de novo assemble a single 47142 bp long contig with coverage of 125.9 and $\mathrm{G}+\mathrm{C}$ content of $30.2 \%$. Seventy-four ORFs all in forward direction were predicted with Glimmer and GeneMarkS. For 18 of these, a function was predicted by BLAST search and 32 were assigned as hypothetical proteins, leaving 24 ORFs (32.4\%) without any significant homologs in BLAST search (as of February 11, 2015). ORFs with predicted 


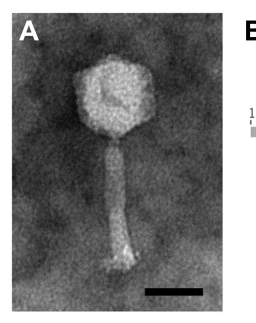

\section{B}

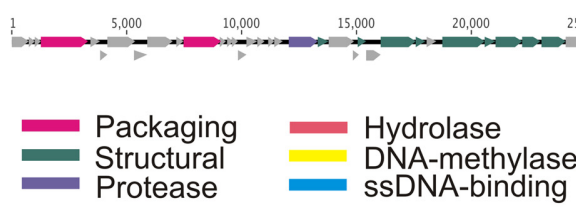

FIGURE 1 | (A) Phage FCL-2 viewed under transmission electron microscopy (TEM; scale bar 40 nm). (B) Graphic representation of the genome organization of FCL-2 with colors indicating the putative functions for open reading frames (ORFs) as shown in the figure.

functions included proteins involved in packaging (terminase and phage portal protein; Figure 1 and Supplementary Table S1) and a protease, a DNA-methylase, and an ssDNA-binding protein. No direct lysis genes were detected although a match to a hydrolase gene was received: This could possibly have a role in the lysis of the cell. Most of the predictions corresponded to structural proteins (e.g., tail and tail sheath protein) located from 13338 to $28169 \mathrm{bp}$ in the genome. These structural proteins were found to match the Cellulophaga phage phiSM and matches to seven other Cellulophaga phages were also obtained from these genes. Further, from the predicted hypothetical proteins, one matched the Flavobacterium phage $11 \mathrm{~b}$ and two hits were linked to the genome of prophage $6 \mathrm{H}$ (Castillo et al., 2013). These two prophage $6 \mathrm{H}$-related proteins, IbrA and IbrB, are also found in F. psychrophilum (the host of $6 \mathrm{H})$ and in F. columnare genomes. Additionally, two ORFs upstream from the IbrAB complex were identical to genes found in F. columnare ATTC 49512 genome (accession number in NCBI: NC_016510.2, FCOL_05310 (WP_014165166.1), and FCOL_05310(WP_014165168.1).

\section{Phage Adsorption Test and Stability}

In the adsorption test, $27 \%$ of phage FCL-2 had adsorbed on the cells of F. columnare B185 after $1 \mathrm{~min}$ and $41 \%$ after $10 \mathrm{~min}$. After $1 \mathrm{~h}, 50 \%$ of the added phages had adsorbed, resulting into an estimated rate of adsorption being $0.5 \mathrm{~h}^{-1}$. The stability of FCL-2 titers was not affected by storage temperature (Table 1). After a 6-week period, the titer of the lysate stored at room temperature was less than that of the lysate stored at $6^{\circ} \mathrm{C}$. The overall titer over 6 weeks decreased 10 -fold when stored in Shieh medium or Tris-HCl buffer, and 100-fold when stored in the presence of potassium phosphate.

\section{Effect of Phage Addition on Survival of the Rainbow Trout Population in a Flow-Through System}

To mimic real life conditions at a fish farm, the phage efficiency was tested in pre-infected populations of rainbow trout fingerlings under continuous water flow. The fish were given phage immediately after bacterial exposure (2-hour immersion in bacteria). A significant increase in survival of fish following experimental phage treatments was observed (Figure 2, Table 2). At the end of the experiment (7 days post infection), the mean survival of the fish infected only with $F$. columnare (infection control) was $8.3 \%$. Phage treatment protected the fish from infection and resulted in a $41.7 \%$ (ratio $10: 1$ ) and $50 \%$ (ratio $1: 1$ ) mean survival $(P<0.001$ for all pairwise comparisons against phage-treated groups and infection control; Table 2). Fish in the negative control group (not infected) survived $80-100 \mathrm{~h}$ post infection, after which background mortality was observed due to the experimental conditions, rather than the treatments. Nevertheless, in pairwise comparisons, survival of fish in the negative control group (no bacteria, no phage) did not differ from those receiving phage treatments after bacterial infection.

In the rainbow trout trial, all diseased fish treated with bacteria only were positive for F. columnare rhizoid morphology according to fin samples. The cultivations from the phage-treated fish showed mainly a rough colony morphology (possibly due to the presence of phage in the sample, see Laanto et al., 2012) with occasional rhizoid colonies. All fish not exposed to bacteria were free of F. columnare.

\section{Effect of Phage Addition to the Survival of Zebrafish in a Continuous Infection Model}

To test if zebrafish can potentially be used as a model system to study phage-bacterium interactions, including the host, instead of rainbow trout (due to the poor availability of disease-free fingerlings and sensitivity to laboratory conditions), an infection experiment was performed with individual continuous exposure to bacterium and phage. The survival of the non-infected controls in the experiment was $100 \%$ versus $0 \%$ in the infection control group treated only with bacteria. Phage addition significantly increased fish survival, resulting in $60 \%$ of survival (Figure 3, Table 2).

In bacterial culture samples taken from zebrafish, all fish treated with bacteria only were positive for the virulent rhizoid colony morphology of $F$. columnare. Three of the six dead fish that were treated with phage were positive for $F$. columnare non-virulent rough type (possibly due to the presence of phage in the sample, see Laanto et al., 2012). Further, all the fish in bacteria-free controls were negative for F. columnare.

\section{Phage and Bacterial Counts during Experiments}

Water samples were taken from the experimental aquaria during the rainbow trout experiment. During the rainbow trout population test in a flow-through system, the FCL-2 phage was isolated from the water in at least $1 \times 10^{4} \mathrm{PFU} \mathrm{mL}^{-1}$ even 
TABLE 1 | Phage FCL-2 stability as plaque forming units (PFU) per mL during 6-week storage.

$\begin{array}{lll}\text { RT } & 6^{\circ} \mathrm{C}\end{array}$

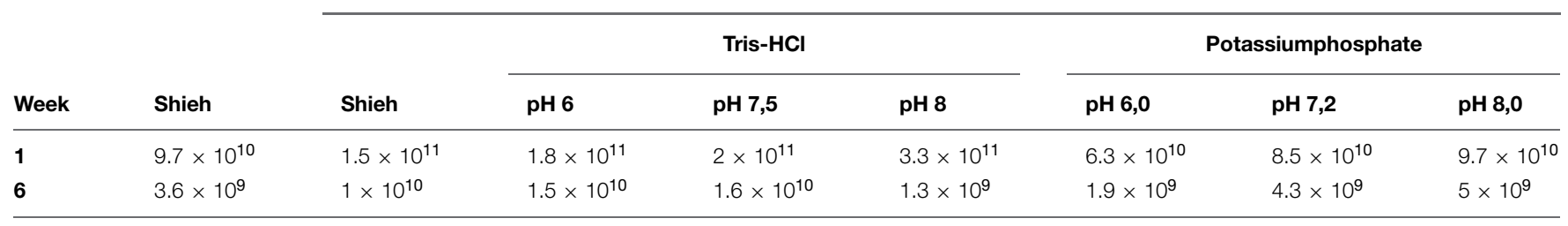

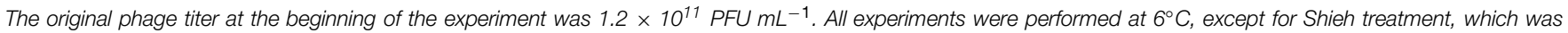
performed at room temperature (indicated as RT).

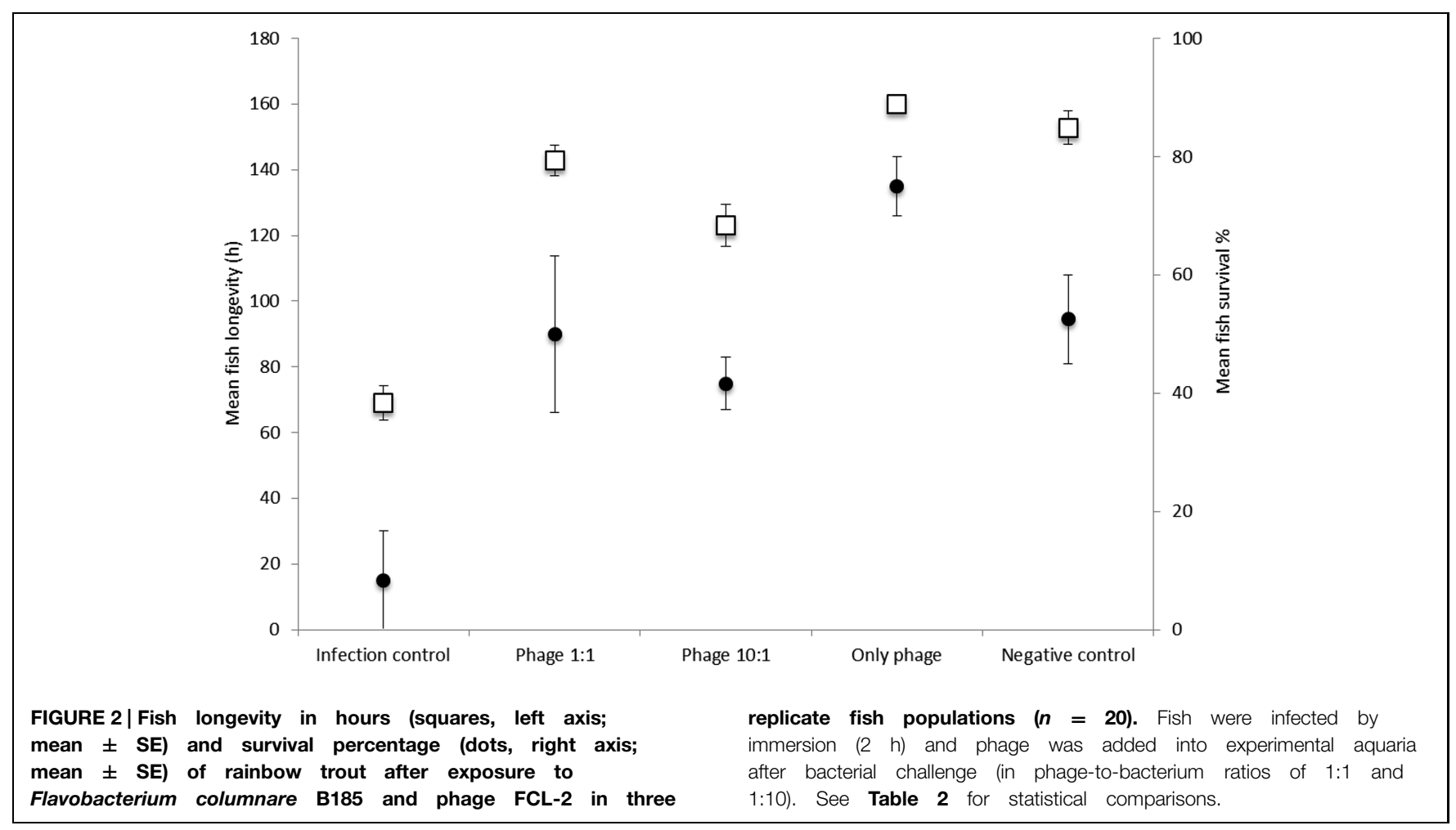

after 24 and $48 \mathrm{~h}$ post infection. This indicates that the phage was able to replicate in the system and was not washed away by the constant water flow. The maximum F. columnare counts in the population experiment were $8.8 \times 10^{2} \mathrm{CFU} \mathrm{mL}^{-1}$ in the bacterial infection control and from the phage-treated aquaria, $2.7 \times 10^{2} \mathrm{CFU} \mathrm{mL}{ }^{-1}$. All of the colonies counted were of the rhizoid morphotype. No F. columnare was isolated from the water samples of the bacteria-free control group.

\section{Discussion}

Herein, the first attempts to apply phage therapy against columnaris disease, caused by F. columnare, are presented. The first genome of a phage infecting F. columnare (FCL-2) was sequenced and characterized for its ability to increase fish survival in the presence of the pathogen. Structural proteins of FCL-2 were related to those of Cellulophaga phages. Cellulophaga, a member of the Bacteroidetes group, is a close relative to Flavobacteria
(Holmfeldt et al., 2007). Using FCL-2, it was shown that phages have great potential in controlling columnaris disease in smallscale experimental systems, but also in rainbow trout populations in flow-through tanks.

Thorough characterization of a phage is essential for its therapeutic use in order to avoid unwanted interactions that might increase the virulence of its bacterial host (Gill and Hyman, 2010). Genome sequencing revealed that a third of the phage ORFs' had no homologs in the database, which is typical for environmental phage genomes (Hurwitz and Sullivan, 2013). Only few ORFs of the FCL-2 phage were related to Flavobacterium phages, most probably due to the low number of these phage genomes available. A gene possibly related to host lysis (hydrolase) was identified in the FCL-2 genome. Clear signs of possible integration to host genome (integrases) or repressors were absent, and lysogeny of the host after exposure to the phage has not been detected (Laanto et al., 2012). A few host hypothetical proteins were identified, including proteins of unknown function, IbrA and B (Supplementary Table S1). In 
TABLE 2 | Statistics of pairwise comparisons in fish survival in phage therapy experiments against Flavobacterium columnare in rainbow trout (Oncorhynchus mykiss) and zebrafish (Danio rerio) using Kaplan-Meier survival analysis, pairwise log rank Mantel Cox test.

\begin{tabular}{|c|c|c|c|c|}
\hline \multirow[t]{2}{*}{ Experiment and overall statistics } & \multirow[t]{2}{*}{ Treatment } & \multicolumn{3}{|c|}{ Statistics for pairwise comparisons } \\
\hline & & Infection control & Phage 1:1 & Phage 1:10 \\
\hline \multirow[t]{4}{*}{ Rainbow trout, population } & Negative control & $x^{2}=49.272, p<0.001$ & NS & NS \\
\hline & Phage 1:1 & $x^{2}=57.235, p<0.001$ & & \\
\hline & Phage 1:10 & $x^{2}=31.824, p<0.001$ & NS & \\
\hline & Only phage & $x^{2}=64.390, p<0.001$ & $\chi^{2}=6.741, p=0.009$ & $x^{2}=12.777, p<0.001$ \\
\hline \multirow[t]{2}{*}{ Zebra fish, continuous infection } & Negative control & $x^{2}=26.199, p<0.001$ & $x^{2}=4.9542, p<0.026$ & \\
\hline & Phage 1:1 & $\chi^{2}=17.853, p<0.001$ & & \\
\hline
\end{tabular}

P-values greater than 0.05 are designated as non-significant (NS).

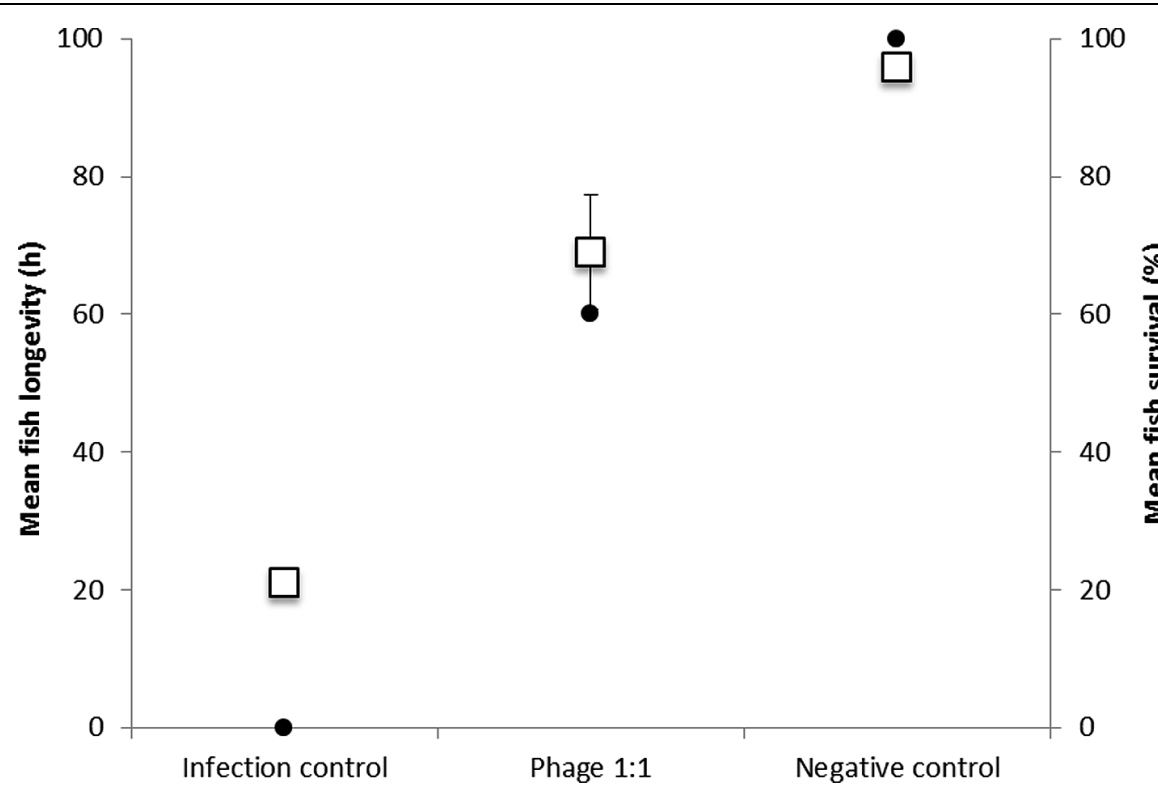

FIGURE 3 | Fish longevity in hours (squares, left axis; mean \pm SE) and survival percentage (dots, right axis; mean \pm SE) of the zebrafish after exposure to F. columnare strain B185 (infection control), B185 and phage FCL-2 (1:1), and to growth medium or phage only (negative control). See Table 2 for statistical comparisons.

the genome analysis of $F$. psychrophilum prophage $6 \mathrm{H}$ it was hypothesized that these two proteins could be possible virulence factors due to their relation to the IbrAB complex in Escherichia coli (Castillo et al., 2013). This complex is possibly involved in host-pathogen interactions and related to resistance to serum and Ig-binding (Sandt and Hill, 2000). Interestingly, IbrA and IbrB and the two ORFs located upstream can also be found in the sequenced genome of F. columnare ATTC 49512, indicating a common origin for these regions. Clearly, more studies are needed to understand the phage life cycles and phage-bacterium interactions in F. columnare.

The results from phage therapy trials in animal production (e.g., in poultry, swine, and cattle) have given encouraging results (Smith and Huggins, 1983; Berchieri et al., 1991; Barrow et al., 1998; Jamalludeen et al., 2009; Santos et al., 2010), similar to phage therapy studies against fish diseases (Nakai and Park, 2002; Park and Nakai, 2003; Higuera et al., 2013; Khairnar et al., 2013). The interest on efficiency of phages against F. psychrophilum
(Stenholm et al., 2008; Castillo et al., 2012) and F. columnare (Laanto et al., 2012; Prasad and Kumar, 2012) has been recently increasing, reflecting the global concern toward flavobacterial pathogens in aquaculture. Generally, the efficiency of a phage as a potential therapeutic is measured by its capacity to destroy bacterial cells at the site of bacterial infection (Levin and Bull, 2004). Previous studies have administered the phages via fish feed and injection (Nakai et al., 1999; Park and Nakai, 2003; Castillo et al., 2012; Kim et al., 2015), which could be laborious when handling large numbers of fish. However, as columnaris disease is mainly external, phages could be also applied directly in the water. Herein, a significant increase was observed in the survival of zebrafish and rainbow trout when the phage was applied in the water shortly after bacterial exposure. When the phage was added into aquaria directly after bacteria, zebra fish survival increased most likely due to a decrease in bacterial infection dose. In contrast, in the rainbow trout experiment, bacteria were allowed to colonize the fish for $2 \mathrm{~h}$ prior to placing them in the 
experimental flow-through tanks where the phage was added. Hence, the increase in fish survival was likely caused by the association of phage and bacteria on fish surfaces rather than via direct effects on infection dose, although the presence of phage in the water is also likely to reduce the transmission of disease between individual fish. Surprisingly, the phage was isolated from the tank water 2 days post infection, indicating that it can persist and replicate in the tanks despite water flow when host bacteria are present. Furthermore, the FCL-2 titer remained stable over a 6-week period, indicating promising persistence and storage qualities required for the development of therapeutic applications in aquaculture.

Bacteria have developed multiple mechanisms against phage infection (Samson et al., 2013); nevertheless, in the continuous arms race between a phage and its host, phages co-evolve to outcompete these mechanisms. Therefore, resistance to a certain phage may not be a problem in phage therapy (Örmälä and Jalasvuori, 2013), especially as maintaining resistance can be costly for bacteria (Laanto et al., 2012, reviewed in Koskella and Brockhurst, 2014). Indeed, our previous results suggest that following strong phage selection $F$. columnare changes colony morphotype (Laanto et al., 2012). Rapid development of phage resistance may thus not be a problem in F. columnare as the resistant cells are not capable of causing disease in fish (Laanto et al., 2012). However, the phageresistant rough morphotype has not been isolated from disease outbreaks, indicating that environmental conditions outside the laboratory influence the evolution or persistence of phage resistance of F. columnare at fish farms. Therefore, more studies on phage resistance mechanisms in this fish pathogen are needed.

The phages isolated against $F$. columnare strains are very host specific when compared to Flavobacterium sp. phages from fish farms and outside the fish farming environment (Laanto et al., 2011). This is promising as it suggests that other bacterial species would not be affected. As Meaden and Koskella (2013) indicate, the possibility that other species of bacteria might be influenced should be taken into account. Although the present study shows that phages significantly increased rainbow trout survival in flow-through water, the condition most relevant for fish farming, there are still many aspects that need to be optimized before reaching production scale. First, the population structure of $F$. columnare at farms is complex and several strains cooccur and may co-infect fish (Suomalainen et al., 2006; Kunttu et al., 2012). Therefore, multiple phages and their associations with the host bacteria need to be characterized and tested for efficiency in mixed infections and to prevent evolution of phage resistance. Second, although phage administration through water is relatively simple, the water masses that need to be maintained saturated are large and phage will be quickly diluted. Since our data suggest that phages are able to persist in flow-through tanks, this challenge may not be insurmountable, especially if phages are used to reducing the infective bacterial dose in the tanks. Similarly, the timing of treatment needs to be optimized, as fish in the rearing units are often at different stages of infection during an outbreak. Problems related to enrichment of phage FCL-2 in liquid culture could be a severe problem concerning the larger scale production of phages for phage therapy, at least when using this specific phage. Also, F. columnare is a slowgrowing bacterium, with a doubling time approximately of $10 \mathrm{~h}$ (Zhang et al., 2014), which could bring extra challenges for production scale. Further, the optimal dose of phage (phagebacterium ratio) is crucial for treatment efficacy and needs to be evaluated, a fact not thoroughly considered in early phage therapy trials (Carlton, 1999). Despite these challenges in the application of phage therapy in aquaculture, it would be worthwhile to assess whether phage therapy could be combined with other treatments. If phage therapy could decrease the bacterial infection dose during disease outbreaks and reduce the risk of transmission, the need for antibiotic treatment could be delayed or targeted to smaller groups of infected individuals. In the long run, this would lead to a reduction in antibiotics use in aquaculture.

\section{Conclusion}

The phage therapy has potential as an efficient and sustainable disease management method in the case of columnaris disease and aquaculture in general. It is shown herein that $F$. columnare and its phage form a good model for the study of phage therapy as the disease and treatment can be studied in the relevant hosts. This model could be used to study the ecological and evolutionary effects of phage therapy. Further, aquaculture conditions with high population densities of fish hosts can thus be replicated in the laboratory. Finally, using zebrafish as a model host could extend the benefits of the experimental system to include the fish host immune response during phage therapy.

\section{Author Contributions}

EL, JB, and L-RS designed the study. EL performed the experiments. EL, JR, and L-RS analyzed the data. EL and L-RS prepared the tables and figures and wrote the manuscript. All authors edited the manuscript.

\section{Acknowledgments}

This work was supported by the Finnish Centre of Excellence Program of the Academy of Finland, the CoE in Biological Interactions 2012-2017 (\#252411), and by Academy of Finland grants \#251106 (JB) and \#272995 (L-RS). The authors wish to thank Dr. Heidi Kunttu, Reetta Penttinen, MSc, Hanna Kinnula, MSc, Katja Neuvonen, MSc, Ms. Heidi Pirttinen, Ms. Kati Mäkelä, and Mr. Petri Papponen for assistance in the laboratory.

\section{Supplementary Material}

The Supplementary Material for this article can be found online at: http://journal.frontiersin.org/article/10.3389/fmicb. 2015.00829 


\section{References}

Abedon, S. T., Kuhl, S. J., Blasdel, B. G., and Kutter, E. M. (2011). Phage treatment of human infections. Bacteriophage 1, 55-65. doi: 10.4161/bact.1.2.15680

Adams, M. H. (1959). Bacteriophages. New York, NY: Interscience Publishers, Inc.

Altschul, S. F., Gish, W., Miller, W., Myers, E. W., and Lipman, D. J. (1990). Basic local alignment search tool. J. Mol. Biol. 215, 403-410. doi: 10.1016/S00222836(05)80360-2

Barrow, P., Lovell, M., and Berchieri, A., Jr. (1998). Use of lytic bacteriophage for control of experimental Escherichia coli septicemia and meningitis in chickens and calves. Clin. Diagn. Lab. Immunol. 5, 294-298.

Berchieri, A. Jr., Lovell, M. A., and Barrow, P. A. (1991). The activity in the chicken alimentary tract of bacteriophages lytic for Salmonella typhimurium. Res. Microbiol. 142, 541-549. doi: 10.1016/0923-2508(91)90187-F

Bernardet, J. F. (1997). Immunization with bacterial antigens: Flavobacterium and Flexibacter infections. Dev. Biol. Stand. 90, 179-188.

Bostock, J., McAndrew, B., Richards, R., Jauncey, K., Telfer, T., Lorenzen, K., et al. (2010). Aquaculture: global status and trends. Philos. Trans. R. Soc. B 365, 2897-2912. doi: 10.1098/rstb.2010.0170

Buschmann, A. H., Tomova, A., López, A., Maldonado, M. A., Henríquez, L. A., Ivanova, L., et al. (2012). Salmon aquaculture and antimicrobial resistance in the marine environment. PLoS ONE 7:e42724. doi: 10.1371/journal.pone.0042724

Cabello, F. C., Godfrey, H. P., Tomova, A., Ivanova, L., Dölz, H., Millanao, A. et al. (2013). Antimicrobial use in aquaculture re-examined: its relevance to antimicrobial resistance and to animal and human health. Environ. Microbiol. 15, 1917-1942. doi: 10.1111/1462-2920.12134

Carlton, R. M. (1999). Phage therapy: past history and future prospects. Arch. Immunol. Ther. Exp. 47, 267-274.

Castillo, D., Espejo, R., and Middelboe, M. (2013). Genomic structure of bacteriophage $6 \mathrm{H}$ and its distribution as prophage in Flavobacterium psychrophilum strains. FEMS Microbiol. Lett. 351, 51-58. doi: 10.1111/15746968.12342

Castillo, D., Higuera, G., Villa, M., Middelboe, M., Dalsgaard, I., Madsen, L., et al. (2012). Diversity of Flavobacterium psychrophilum and the potential use of its phages for protection against bacterial cold water disease in salmonids. J. Fish Dis. 35, 193-201. doi: 10.1111/j.1365-2761.2011.01336.x

Declercq, A. M., Haesebrouck, F., Van den Broeck, W., Bossier, P., and Decostere, A. (2013). Columnaris disease in fish: a review with emphasis on bacterium-host interactions. Vet. Res. 44:27. doi: 10.1186/1297-971 6-44-27

Decostere, A., Haesebrouck, F., and Devriese, L. A. (1997). Shieh medium supplemented with tobramycin for selective isolation of Flavobacterium columnare (Flexibacter columnaris) from diseased fish. J. Clin. Microbiol. 35, 322-324.

Di Cesare, A., Luna, G. M., Vignaroli, C., Pasquaroli, S., Tota, S., Paroncini, P., et al. (2013). Aquaculture can promote the presence and spread of antibiotic-resistant Enterococci in marine sediments. PLoS ONE 8:e62838. doi: 10.1371/journal.pone.0062838

Gill, J. J., and Hyman, P. (2010). Phage choice, isolation, and preparation for phage therapy. Curr. Pharm. Biotechnol. 11, 2-14. doi: 10.2174/138920110790725311

Higuera, G., Bastías, R., Tsertsvadze, G., Romero, J., and Espejo, R. T. (2013). Recently discovered Vibrio anguillarum phages can protect against experimentally induced vibriosis in Atlantic salmon, Salmo salar. Aquaculture 392-395, 128-133. doi: 10.1016/j.aquaculture.2013.02.013

Hollis, A., and Ahmed, Z. (2013). Preserving antibiotics, rationally. New Engl. J. Med. 369, 2474-2476. doi: 10.1056/NEJMp1311479

Holmfeldt, K., Middelboe, M., Nybroe, O., and Riemann, L. (2007). Large variabilities in host strain susceptibility and phage host range govern interactions between lytic marine phages and their Flavobacterium hosts. Appl. Environ. Microbiol. 73, 6730-6739. doi: 10.1128/AEM.01399-07

Hurwitz, B. L., and Sullivan, M. B. (2013). The Pacific Ocean Virome (POV): a marine viral metagenomic dataset and associated protein clusters for quantitative viral ecology. PLOS ONE 8:e57355. doi: 10.1371/journal.pone.00 57355

Jamalludeen, N., Johnson, R. P., Shewen, P. E., and Gyles, C. L. (2009). Evaluation of bacteriophages for prevention and treatment of diarrhea due to experimental enterotoxigenic Escherichia coli O149 infection of pigs. Vet. Microbiol. 136, 135-141. doi: 10.1016/j.vetmic.2008.10.021
Jones, J. B., Vallad, G. E., Iriarte, F. B., Obradovic, A., Wernsing, M. H., Jackson, L. E., et al. (2012). Considerations for using bacteriophages for plant disease control. Bacteriophage 2, 208-214. doi: 10.4161/bact. 23857

Khairnar, K., Raut, M. P., Chandekar, R. H., Sanmukh, S. G., and Paunikar, W. N. (2013). Novel bacteriophage therapy for controlling metallo-beta-lactamase producing Pseudomonas aeruginosa infection in catfish. BMC Vet. Res. 9:264. doi: 10.1186/1746-6148-9-264

Kim, J. H., Choresca, C. H., Shin, S. P., Han, J. E., Jun, J. W., and Park, S. C. (2015). Biological control of Aeromonas salmonicida subsp. salmonicida infection in rainbow trout (Oncorhynchus mykiss) using aeromonas phage PAS-1. Transbound Emerg. Dis. 62, 81-86. doi: 10.1111/tbed.12088

Koskella, B., and Brockhurst, M. A. (2014). Bacteria-phage coevolution as a driver of ecological and evolutionary processes in microbial communities. FEMS Microbiol. Rev. 38, 916-931. doi: 10.1111/1574-6976.12072

Kunttu, H. M. T., Sundberg, L.-R., Pulkkinen, K., and Valtonen, E. T. (2012). Environment may be the source of Flavobacterium columnare outbreaks at fish farms. Environ. Microbiol. Rep. 4, 398-402. doi: 10.1111/j.17582229.2012.00342.x

Kunttu, H. M. T., Valtonen, E. T., Jokinen, E. I., and Suomalainen, L.-R. (2009). Saprophytism of a fish pathogen as a transmission strategy. Epidemics 1, 96-100. doi: 10.1016/j.epidem.2009.04.003

Laanto, E., Bamford, J. K. H., Laakso, J., and Sundberg, L.-R. (2012). Phage-driven loss of virulence in a fish pathogenic bacterium. PLoS ONE 7:e53157. doi: 10.1371/journal.pone.0053157

Laanto, E., Sundberg, L.-R., and Bamford, J. K. H. (2011). Phage specificity of the freshwater fish pathogen Flavobacterium columnare. Appl. Environ. Microbiol. 77, 7868-7872. doi: 10.1128/AEM.0557411

Levin, B. R., and Bull, J. J. (2004). Population and evolutionary dynamics of phage therapy. Nat. Rev. Microbiol. 2, 166-173. doi: 10.1038/nrmicro822

Meaden, S., and Koskella, B. (2013). Exploring the risks of phage application in the environment. Front. Microbiol. 4:358. doi: 10.3389/fmicb.2013.00358

Nakai, T., and Park, S. C. (2002). Bacteriophage therapy of infectious diseases in aquaculture. Res. Microbiol. 153, 13-18. doi: 10.1016/S0923-2508(01) 01280-3

Nakai, T., Suqimoto, R., Park, K. H., Matsuoka, S., Mori, K., Nishioka, T., et al. (1999). Protective effects of bacteriophage on experimental Lactococcus garvieae infection in yellowtail. Dis. Aquat. Org. 37, 33-41. doi: 10.3354/dao0 37033

Örmälä, A.-M., and Jalasvuori, M. (2013). Phage therapy: should bacterial resistance to phages be a concern, even in the long run? Bacteriophage 3:e24219. doi: 10.4161/bact.24219

Park, S. C., and Nakai, T. (2003). Bacteriophage control of Pseudomonas plecoglossicida infection in ayu Plecoglossus altivelis. Dis. Aquat. Org. 53, 33-39. doi: 10.3354/dao053033

Prasad, Y., and Kumar, A. D. (2012). Isolation and efficacy evaluation of virulent bacteriophages specific to fish pathogenic bacterium, Flavobacterium columnare. J. Appl. Anim. Res. 38, 169-172. doi: 10.1080/09712119.2010.105 39505

Pulkkinen, K., Suomalainen, L.-R., Read, A. F., Ebert, D., Rintamäki, P., and Valtonen, E. T. (2010). Intensive fish farming and the evolution of pathogen virulence: the case of columnaris disease in Finland. Proc. Biol. Sci. 277, 593-600. doi: 10.1098/rspb.2009.1659

Samson, J. E., Magadán, A. H., Sabri, M., and Moineau, S. (2013). Revenge of the phages: defeating bacterial defences. Nat. Rev. Microbiol. 11, 675-687. doi: $10.1038 /$ nrmicro3096

Sandt, C. H., and Hill, C. W. (2000). Four different genes responsible for nonimmune immunoglobulin-binding activities within a single strain of Escherichia coli. Infect. Immun. 68, 2205-2214. doi: 10.1128/IAI.68.4.22052214.2000

Santos, M. A. (1991). An improved method for the small scale preparation of bacteriophage DNA based on phage precipitation by zinc chloride. Nucl. Acids Res. 19, 5442-5442. doi: 10.1093/nar/19.19.5442

Santos, T. M. A., Gilbert, R. O., Caixeta, L. S., Machado, V. S., Teixeira, L. M., and Bicalho, R. C. (2010). Susceptibility of Escherichia coli isolated from uteri of postpartum dairy cows to antibiotic and environmental bacteriophages. Part II: in vitro antimicrobial activity evaluation of a bacteriophage cocktail and several antibiotics. J. Dairy Sci. 93, 105-114. doi: 10.3168/jds.2009-2299 
Smith, H. W., and Huggins, M. B. (1983). Effectiveness of phages in treating experimental Escherichia coli diarrhoea in calves, piglets and lambs. Microbiology (Reading, Engl.) 129, 2659-2675. doi: 10.1099/00221287-12982659

Stenholm, A. R., Dalsgaard, I., and Middelboe, M. (2008). Isolation and characterization of bacteriophages infecting the fish pathogen Flavobacterium psychrophilum. Appl. Environ. Microbiol. 74, 4070-4078. doi: 10.1128/AEM.00428-08

Suomalainen, L.-R., Kunttu, H., Valtonen, E. T., Hirvelä-Koski, V., and Tiirola, M. (2006). Molecular diversity and growth features of Flavobacterium columnare strains isolated in Finland. Dis. Aquat. Org. 70, 55-61. doi: 10.3354/dao070055

Tripathi, N. K., Latimer, K. S., Gregory, C. R., Ritchie, B. W., Wooley, R. E., and Walker, R. L. (2005). Development and evaluation of an experimental model of cutaneous columnaris disease in koi Cyprinus carpio. J. Vet. Diagn. Invest. 17, 45-54. doi: 10.1177/104063870501700109

Welker, T. L., Shoemaker, C. A., and Arias, C. R. (2005). Transmission and detection of Flavobacterium columnare in channel catfish Ictalurus punctatus. Dis. Aquat. Organ. 63, 129-138. doi: 10.3354/dao063129
WHO. (2014). "Resistance to antibacterial drugs in selected bacterial of international concern," in Antimicrobial Resistance: Global Report on Surveillance 2014, eds C. Hilary and M. Lindsay (Geneva: WHO).

Zhang, J., Laakso, J., Mappes, J., Laanto, E., Ketola, T., Bamford, J. K. H., et al. (2014). Association of colony morphotypes with virulence, growth and resistance against protozoan predation in the fish pathogen Flavobacterium columnare. FEMS Microbiol. Ecol. 89, 553-562. doi: 10.1111/1574-6941.12356

Conflict of Interest Statement: The authors declare that the research was conducted in the absence of any commercial or financial relationships that could be construed as a potential conflict of interest.

Copyright (C) 2015 Laanto, Bamford, Ravantti and Sundberg. This is an open-access article distributed under the terms of the Creative Commons Attribution License (CC BY). The use, distribution or reproduction in other forums is permitted, provided the original author(s) or licensor are credited and that the original publication in this journal is cited, in accordance with accepted academic practice. No use, distribution or reproduction is permitted which does not comply with these terms. 